\title{
The Reflection of Ship Demolition Prices to Construction Costs in Turkey
}

\author{
Abdullah Açık ${ }^{1}$ (D) Esra Baran ${ }^{1^{*}}$ (D) \\ ${ }^{1}$ Dokuz Eylül University, Maritime Faculty, Buca, İzmir, Turkey
}

\section{ARTICLE INFO}

Article History:

Received: 30.03.2019

Received in revised form: 31.05.2019

Accepted: 17.06.2019

Available online: 20.06.2019

Keywords:

Construction cost

Demolition price

Exchange rate

\begin{abstract}
A B S T R A C T
The ship demolition sector is one of the major suppliers of the steel market, even though its share in the total scrap market is very small. As the sector is a supplier of the steel market, it is inevitable that the price changes will be reflected in the construction sector, which is one of the largest steel customers. In this context, it is aimed in this study to determine whether the changes in demolition prices of Turkey, which is one of the main ship demolition locations in the world, have an effect on the construction costs in the country. In order to investigate possible relationships, Turkish demolition prices and Construction Cost Index (CCI) variables are used. The dataset covers the dates between January 2015 and December 2018, and consists of 48 monthly observations. Asymmetric causality test is used to determine the causal relationship between the variables by separating the shocks they contain as positive and negative. The econometric relationship is analyzed with both the USD currency price offered by Turkish demolition businesses and the corresponding TL currency prices in order to diversify the results. According to the results, causality relation from positive shocks in USD based demolition prices to the positive shocks in construction costs index is determined. In addition, there are causalities from positive shocks in TL based demolition prices to the positive shocks in construction cost index, and from negative shocks in demolition prices to the negative shocks in the index. This situation shows that the foreign exchange rates also play an important role in shaping the costs of the construction sector.
\end{abstract}

Please cite this paper as follows:

Açı, A., Baran, E. (2019). The Reflection of Ship Demolition Prices to Construction Costs in Turkey. Marine Science and Technology Bulletin, 8(1): 23-29.

\section{Introduction}

The scrap sector meets some part of the demand for steel by supplying the scrapped steel to the market (Merikas et al., 2015). Products obtained from this scrapped steel are generally used as construction iron. From this point of view, it is not unreasonable to say that changes in scrap iron prices cause changes in the iron supply costs of the construction sector, which consequently cause a change in the general cost of construction.
A relatively small portion of the scrap sector is obtained from ship demolition activities (Mikelis, 2013). Ships that have completed their economic life are sent to demolition and become both an income source for shipowners and a steel source for the construction sector (Strandenes, 2010). The demolition activities are carried out in a few locations across the world such as Bangladesh, China, India, Pakistan, and Turkey, and these countries offer a specific price per tonne to attract ships. This offered price is affected by both maritime market (Mikelis, 2007; Açık and Başer, 2018a) and steel market (Mikelis,

\footnotetext{
* Corresponding author

E-mail address: abdullah.acik@deu.edu.tr (A. Açık)
} 
2013), however these interactions are not covered by this study. In this study, the aim is to examine the causal relationship between the proposed price for demolition by Turkish demolition businesses and the construction costs in the country. For representing construction costs in Turkey, Construction Cost Index (CCI) published by TURKSTAT is used.

The relationship between the price of ship demolition and the construction cost is examined and diversified in two ways. The first one is examining with USD currency, which is the original demolition price, and the second one is examining with corresponding TL value of the original demolition price. Taking into account the possibility of losing their linearity since the financial series are exposed to many unexpected events and shocks, the relationship between variables is examined by nonlinear causality analysis in addition to the linear causality analysis. It is thought that the implementation of the two kind of analyses is functional in order to discover whether the relationship between the variables is linear and to prove the advantage of the method used. The selected nonlinear analysis is the asymmetric causality analysis, which enables to determine the causality relationship between the positive and negative shocks included by the considered variables. This feature is important since it is natural for players in the market to react differently depending on the type of shock.

No significant relationship can be obtained according to the linear causality analysis, and the linearity of the series is investigated with the Brock, Dechert and Scheinkman (BDS) test. Since the BDS test reveals that the series are not linear, the asymmetric causality test is applied. According to the results of the analyses, significant results are obtained in both cases. Positive shocks in demolition prices with USD currency are the cause of positive shocks in construction cost index. On the other hand, in the case of corresponding TL values, positive shocks in the demolition prices are the causes of positive shocks in the construction cost index, and negative shocks in the demolition prices are the causes of negative shocks in construction cost index. This situation shows that the foreign exchange rates also play an important role in shaping the costs of the construction sector as well as the international prices. Increasing shocks in USD based prices are reflected in the construction sector costs immediately, while lowering shocks are not reflected. Instead, the lowering shocks in TL based prices have led to lowering shocks in the cost of construction sector due to the drop in the exchange rates.

The related literature is evaluated in the second section of the study and the current study is positioned. The method used in the study is introduced and the reasons for its use are expressed in the third section. The relevant data set is examined and the results obtained from analyses are presented in the fourth section. The results are evaluated and several policy implications are proposed in the last section.

\section{Literature Reviews}

As mentioned by Karlis and Polemis (2016) ship demolition market literature is predominantly centered around the environmental and regulatory parts of the point. There are fairly limited and rare studies focused on the economic analysis of the sector and the factors affecting demolition sector. In summary, the main topics related to the demolition industry in the literature; the probability of a vessel to be scrapped in major demolition yards in the world and impact of several factors on that probability (Knapp et al., 2008), the relationship between international scrap price and demolition price (Kagkarakis et al., 2016), the process of ship sale for demolition (Karlis and Polemis, 2016), the relationship between freight levels and the amount of vessel sent to the demolition (Açlk and Başer, 2017), the impact of supply side on the price formation in demolition industry (Kagkarakis, 2017), the relationship between the demolition price and the freight level in the dry bulk market (Açık and Başer, 2018a), market efficiency in ship demolition prices (Açık and Başer, 2018b), ship demolition decisions of individual shipowners in different market conditions (Yin and Fan, 2018). Also, some evaluations are made about ship demolition market through various statistical data in some studies (Buxton, 1991; Mikelis, 2007; Mikelis, 2013).

The study of Knapp et al. (2008) provides useful insights into the dynamics of the ship demolition market by applying econometric analysis with a comprehensive data set covering 29 -year period and collected from several sources. The findings conclude a negative relationship with earnings which means an increase in earnings decreases the probability of a ship being demolished, and a positive relationship with demolition prices which means an increase in the demolition price will lead to a higher probability of ships being scrapped.

Kagkarakis et al. (2016) have investigated the causal relationship between international steel-scrap prices and ship demolition prices. Their findings have resulted that the ship demolition price is also determined by other market conditions such as the international steelscrap trade. The steel-scrap imports in the ship demolition regions are quite higher than the volume of scrap-metal obtained from ship demolition. They have also suggested that the signals provided by the global steel-scrap prices to the ship demolition market can be taken into consideration by shipowners and practitioners.

Karlis and Polemis (2016) have analyzed the ship sale process for demolition by focusing on the monetary flows of the ships sale activity. They have stated that the ship sale decision for demolition market is oriented by some factors, for instance the state of the market cycle, which is considered to be the most important one. The ship sale decision of the shipowner will be affected by the offered ship scrapping price.

In a study conducted by Açık and Başer (2017), the relationship between the freight rates and the amount of vessel sent to the scrapping is investigated through correlation and regression analysis. In theory, the decline of revenues in the market causes the operational activities of old and obsolete ships to be unsustainable, therefore when the freight rates fall, there is an increase in the amount of vessel going to scrapping. As a result of analyses carried out by the authors, they confirm the negative relationship between the freight rates and the amount of ship sent to the scrapping.

In the study of Kagkarakis (2017) the effects of both the supply and the demand factors on the ship-demolition price formation has been investigated by the vector autoregressive model method in the crude tanker and the bulk carrier markets. The findings of the study have 
showed that the supply side factors have limited impact on the price formation in the demolition industry.

In another study conducted by Açı and Başer (2018a), the relationship between the scrap prices and the freight rates has been examined. The increase in freight rates implies an economic recovery, as the demand for transportation activities has increased. In addition, as mentioned in the previous studies by the same authors, the increase in freight rates cause a decrease in the amount of vessel sent to the demolition (Açlk and Başer, 2017). Increased steel demand caused by the economic recovery and the shortage of ships in the demolition yards due to the buoyant freight market conditions may cause an increase in the offered demolition prices. In the results of the analyses carried out in this context, the positive relationship between freight rates and demolition prices is confirmed by the authors.

Açlk and Başer (2018b) have investigated the validity of the weak form Efficient Market Hypothesis in the demolition prices. Being efficient in the weak form means that the prices do not have a relationship with their historical values and they move randomly. However, some demolition market factors such as its small share in the general scrap industry (Mikelis, 2013), its close relationship with general scrap prices (Mikelis, 2007; Açık and Başer 2018b), its relationship with freight market conditions (Buxton, 1991; Açı and Başer, 2017), its limited locations in the word, and its sensitivity to steel industry demand (Kagkarakis et al., 2016) are said to be prevent the prices from moving randomly. The authors have concluded that the demolition prices of five major demolition locations (Bangladesh, China, India, Pakistan, and Turkey) are not efficient in the weak form as a result of the BDS test.

The individual shipowners' ship demolition decisions and their behavioral changes after the financial crisis period have been analyzed by Yin and Fan (2018). The findings of the survival analysis models (the one period before the financial crisis in 2008 and one after) have indicated that while the main actors of ship demolition market are the shipowners from developed countries before the financial crisis, more shipowners from developing countries started to get involved after the crisis period.

One of the main customers of the steel market is the construction industry. Although the share of ship scrap remains small in the steel industry, it is not a poor opinion to think that it affects the general market. Therefore, it is likely that there is a relationship between ship demolition prices and construction costs. However, as can be seen from the literature reviewed, no studies that examined this possible relationship econometrically have been found. In this regard, this study offers an original contribution to the literature by examining the relationship by the case of Turkish industries. Moreover, another important point that increases the originality of the study is the method used. Due to the partly complex nature of the ship demolition market affected by both the maritime market and the steel market, it is difficult to establish linear relations. In this context, the asymmetric causality test, which provides the opportunity to examine the relationships in a nonlinear manner by separating the shocks in the variables as positive and negative, strengthens the findings of the study.

\section{Methodology}

In accordance with the purpose of the study, used methods respectively are standard linear causality analysis, BDS test and asymmetric causality analysis. Standard linear causality analysis is used both to determine the direction of the relationship between variables and to show the possible insufficiency of linear methods in determination causal relationships in the maritime markets. The BDS test is used to examine whether the series are linear or not, in addition to the information obtained from distributions of the variables. Finally, the asymmetric causality test is used to examine the possible nonlinear relationship between the variables by separating the shocks as negative and positive.

The most basic method of investigating causality relationships between variables is the standard linear causality analysis developed by Granger (1969). This method tests the causality relationship between the two variables by investigating whether the past values of first variable can explain the current and future values of the second one (Yu et al., 2015). In other words, the Granger causality matters if there is a correlation between the present value of the first variable and the past values of the second one (Chiou-Wei, 2008). However, studies conducted in later periods have showed that linear methods may be insufficient to detect non-linear relationships (Adıgüzel et al., 2013; Bal and Rath, 2015; Kumar, 2017). This deficiency constitutes an important obstacle, especially considering that the economic and financial series in the today's globalized world are constantly exposed to unexpected shocks and crises.

The standard causality test can be used in a healthy way by verifying that the structure of the series is linear. In order to test the linearity structure, the distribution of the series can be examined, or some additional tests can be used. One of the most common methods used for investigating the nonlinearity is the BDS test developed by Brock, Dechert and Scheinkman (1987). It is applied to the residuals that are separated from an estimated equation, and it checks whether the residuals are independent and identically distributed. The null hypothesis of this test indicates that the series conform to these assumptions (Brock et al., 1996), and the rejection of the null hypothesis indicates that the residues contain some hidden and nonlinear structure. The rejection of the null hypothesis implies that the nonlinear Granger causality test is more appropriate than the linear one (Lim and Ho, 2013).

The nonlinear causality test used in this study is the asymmetrical causality analysis developed by Hatemi-J (2012a). The advantage of this method is that it can separate the shocks included in the variables as positive and negative ones, and investigate the causal relationships between them in four possible combinations; (i) from positive shocks to positive shocks, (ii) from positive shocks to negative shocks, (iii) from negative shocks to negative shocks, and lastly, (iv) from negative shocks to positive shocks. The test constructs cumulative sums of positive and negative shocks in order to determine causal relationships between them (Tugcu and Topcu, 2018), and thus causal impacts of positive shocks and negative shocks can be separated (Shahbaz et al., 2017). This feature is very useful since asymmetric positive and negative shocks can produce different impacts (Hatemi-J, 2012b). In 
addition, players in the market may react differently depending on the type of shock they are exposed to (Hatemi-J, 2012a).

Some initial values must be determined before the asymmetric causality test is applied. Firstly, since this test follows a Toda and Yamamoto (1995) process, it is necessary to determine the appropriate degree of integration (Umar and Dahalan, 2016). Various unit root tests can be used for this, and if there is a unit root in the series, an extra lag is added to the unrestricted VAR models (Hatemi-J and Uddin, 2012). In this study, the augmented Dickey-Fuller (ADF) unit root test developed by Dickey and Fuller (1979) is used. Another value that must be determined before the analysis is the type of information criterion that allows to identify the best model. In this study, one of the most commonly used criteria, Akaike Information Criteria (AIC) is used in both before the implementation of BDS test and asymmetric causality test. The other last two values are the maximum number of lags and the number of bootstrap simulations.

Eviews 10 and GAUSS 10 econometric software packages are used in the analysis process. The former is used in the unit root test, the standard Granger causality test, ARIMA estimation and BDS tests while the latter is used in the asymmetric causality test. In the next section, the process explained here is followed and the results of the analysis are presented.

\section{Results}

Descriptive statistics of the series are presented in Table 1. The dataset covers the dates between January 2015 and December 2018, and consists of 48 monthly observations. As the demolition prices are obtained in US dollar currency, the statistics for the USD / TL parity used to convert them to TL are also included in the table. The term of the demolition prices refers to the US dollars per Light Displacement
Tonnage (LDT) that offered to old or obsolete vessels by the ship demolition operations. The measure of LDT is an indication of the amount of steel contents of the vessels. The total demolition value of the ship is determined by multiplying the offered demolition price by LDT (Allum, 2013).

The Skewness and Kurtosis values in the descriptive statistics also provide information about the types of shock that the variables are mostly exposed. If the value of Kurtosis higher than 3, the sign of Skewness often indicates the type of shocks (news) that is mostly exposed to. When the values of the variables transformed into the return series are examined, it can be seen that CCI and USD variables have positive skewness values, while both other Demo variables have negative values. These results indicate that the construction cost index and the USD / TL parity are more exposed to positive shocks in the covered period. On the other hand, both types of demolition prices are more exposed to negative shocks in the covered period.

It is also possible to obtain information about the linearity of the series from the descriptive statistics. The lack of normal distribution of the series may indicate that they are not linear (Shahbaz et al., 2017) since the linear structures of the series exposed to too many unexpected shocks are deteriorated. The determination of the normal distribution is determined by Jarque-Bera test, and the null hypothesis of this test indicates that the series have a normal distribution. When JB probabilities of return series are examined, the null hypothesis is rejected in all variables, and there is strong evidence that the series are not linear. This information is important because the asymmetric causality test is a nonlinear method. In order to strengthen this information obtained from descriptive statistics, the Brock, Dechert and Scheinkman (BDS) test is also applied to the series in the further process.

Table 1. Descriptive statistics of the data

\begin{tabular}{lrrrrrrrr}
\hline Values & CCI & DEMO & USD & DEM. TL & $\Delta$ LNCCI & $\Delta$ LNDEM & $\Delta$ LNUSD & $\Delta$ LNDEM. TL \\
\hline Mean & 126.1 & 224.4 & 3.55 & 816.3 & 0.01 & -0.00 & 0.01 & 0.01 \\
Median & 121.7 & 231.3 & 3.48 & 709.6 & 0.00 & 0.00 & 0.01 & 0.02 \\
Maximum & 182.8 & 300 & 6.37 & 1552 & 0.07 & 0.16 & 0.18 & 0.15 \\
Minimum & 97.1 & 148 & 2.33 & 435.1 & -0.03 & -0.24 & -0.08 & -0.19 \\
Std. Dev. & 25.2 & 44.1 & 0.93 & 324.0 & 0.01 & 0.08 & 0.04 & 0.08 \\
Skewness & 0.81 & -0.04 & 1.31 & 0.74 & 1.09 & -0.77 & 0.83 & -0.84 \\
Kurtosis & 2.58 & 1.70 & 4.20 & 2.35 & 4.95 & 3.68 & 5.73 & 3.72 \\
Jarque-Bera & 5.62 & 3.38 & 16.7 & 5.20 & 16.9 & 5.58 & 20.0 & 6.58 \\
Probability & 0.06 & 0.18 & 0.00 & 0.07 & 0.00 & 0.06 & 0.00 & 47 \\
Observations & 48 & 48 & 48 & 48 & 47 & 47 & & 47 \\
\multicolumn{2}{c}{ Source: TCMB (2019); TUIK (2019); Athenian Shipbrokers (2019) } &
\end{tabular}

Augmented Dickey-Fuller (1979) test is applied to all series for stationarity control, and the results are presented in Table 2 . The application of this test is essential for 3 reasons; (i) the series must be stationary for the implementation of the standard Granger causality test; (ii) the series must be stationary in order to estimate the ARIMA models and carry out the BDS test on their residuals; (iii) there is no requirement for stationarity of the variables in the asymmetric causality test, however the maximum degree of integration must be known. According to the results of these tests, all variables become stationary when the first differences are taken. This stationarity information also indicates the maximum degree of integration in the asymmetric causality test. 
Table 2. Augmented Dickey-Fuller unit root test results

\begin{tabular}{|c|c|c|c|c|}
\hline \multirow[b]{2}{*}{ Variable } & \multicolumn{2}{|c|}{ Level } & \multicolumn{2}{|c|}{ First Difference } \\
\hline & Intercept & $\begin{array}{l}\text { Trend and } \\
\text { Intercept }\end{array}$ & Intercept & $\begin{array}{c}\text { Trend and } \\
\text { Intercept }\end{array}$ \\
\hline Construction Cost & & & & \\
\hline $\begin{array}{l}\text { Index } \\
\text { Turkish Demolition }\end{array}$ & 0.789 & -2.300 & $-4.920^{* * *}$ & $-4.933^{* * *}$ \\
\hline $\begin{array}{l}\text { Prices (\$) } \\
\text { Turkish Demolition }\end{array}$ & -1.765 & $-3.358^{*}$ & $-2.798^{*}$ & $-2.876^{* * *}$ \\
\hline Prices (TL) & 0.053 & -2.956 & $-6.557^{* * *}$ & $-6.514^{* * *}$ \\
\hline
\end{tabular}
Intercept; -3.18 for ${ }^{*} 10 \%,-3.51$ for ${ }^{* *} 5 \%,-4.17$ for ${ }^{* *} 1 \%$ at Trend and Intercept.

In addition, the causality relationship between variables is also tested by the linear method. The analyses are carried out with stationary variables in both US dollar and TL basis and the results are presented in Table 3. The optimum lags for both tests are determined as 1 according to AIC, SC and HQ information criteria. According to the results obtained, the null hypotheses are rejected in all cases, and neither the USD nor the TL-based causality relationships can be determined. This may be considered to indicate the insufficiency of the linear method to detect nonlinear relationships. In this respect, BDS test, which is commonly used in determination of the non-linearity, is carried out.

Table 3. Standard Granger causality analysis

\begin{tabular}{|c|c|c|c|}
\hline Null Hypothesis: & Obs & F-Statistic & Prob. \\
\hline$\Delta$ LNDEMO does not Granger Cause $\Delta$ LNCCI & \multirow{2}{*}{46} & 0.20123 & 0.6560 \\
\hline$\Delta \mathrm{LNCCI}$ does not Granger Cause $\Delta \mathrm{LNDEMO}$ & & 0.00246 & 0.9607 \\
\hline$\Delta \mathrm{LNDEMOTL}$ does not Granger Cause $\Delta \mathrm{LNC}$ & & 0.59958 & 0.4430 \\
\hline$\Delta \mathrm{LNCCI}$ does not Granger Cause $\Delta \mathrm{LNDEMOTI}$ & & 0.00628 & 0.9372 \\
\hline
\end{tabular}

First of all, all the variables are converted into financial return series by using $R_{i}=\ln _{i}-\ln _{i-1}$. In order to implement the BDS test in the most appropriate way, the deterministic parts of the data must be separated firstly, since the rest of the data after this process is the variance of the series. To separate the deterministic parts, the most appropriate ARIMA model is determined for each variable through lowest AIC (Akaike Information Criteria) values. Then the best models are estimated, and the residuals of the models are separated. Finally, BDS test is applied to these residuals for 6 dimensions in order to determine non-linear structures if any. The null hypothesis of this test indicates that the series contains a non-linear structure, and even if the null hypothesis is rejected in one of the dimensions, it indicates that there is a nonlinear structure in the series. The same process is followed for each variable using the automatic ARIMA forecasting function in an econometric software.

Firstly, the most suitable model for the Construction Cost Index (CCI) variable is determined as the model of ARMA $(1,0)$ with -5.41 AIC value. Then, after the model is estimated, the residuals of the model are subjected to the BDS test and the results are presented in Table 4. According to the results obtained, the null hypotheses in the second and sixth dimensions are rejected and the nonlinear structure in the series is confirmed. Secondly, the most suitable model for Demolition Price in US dollar currency (DEMO) variable determined as the model of ARIMA $(5,5)$ with -2.21 AIC value. According to the results of the BDS test applied to the residuals, the null hypotheses are rejected in the second, third and fifth dimensions. These results confirm the nonlinear structure in this variable. Finally, the most suitable model for Demolition Price in TL currency (DEMOTL) is determined as ARIMA $(3,1)$ model with -2.13 AIC value. According to the BDS test applied to the residuals, the null hypotheses are rejected in the second, fourth and sixth dimensions. Consequently, all variables contain nonlinear structures, which imply the applicability of the nonlinear asymmetric causality test.

Table 4. BDS independence test results

\begin{tabular}{cccc}
\hline Dimension & CCI Prob. & Demo USD Prob. & Demo TL Prob. \\
\hline 2 & $0.0274^{\star \star}$ & $0.0132^{\star *}$ & $0.0905^{\star}$ \\
3 & 0.2596 & $0.0444^{\star *}$ & 0.1056 \\
4 & 0.5452 & 0.1081 & $0.0587^{\star}$ \\
5 & 0.4430 & $0.0872^{\star}$ & 0.1199 \\
6 & $0.0109^{\star \star}$ & 0.3913 & $0.0445^{\star *}$ \\
\hline
\end{tabular}

Then the process of the implementation of the asymmetric causality test begins. Some initial values must be determined before this test is performed, which are the maximum degree of integration (dmax), the maximum lags value, the type of information criterion to choose the most suitable model, and the maximum number of the bootstrap simulation. The dmax value is the maximum difference that must be taken in order to make both variables used in the analysis stationary. Unit root tests are used for the determination of this value, and according to the ADF unit root test results presented in Table 1, all variables become stationary when the first differences are taken. That is, the maximum degree of integration is determined as 1 . The maximum number of lags, which is the other value to be determined, is set to 4 since the number of the observations in the analysis is small and the data frequency is monthly. The type of information criteria used to select the most suitable model is determined as Akaike Information Criteria (AIC), which is one of the most widely used one. Lastly, the maximum number of bootstrap simulations is selected as 1000. Then, the asymmetric causality test is applied.

The results of the asymmetric causality test are presented in Table 5. According to the results, while one significant causality has been determined from the USD based demolition price to the Construction Cost Index, two significant causal relationships have been determined from the TL based demolition price. The positive shocks in the USD Demo variable are the cause of positive shocks in the CCI variable. Increasing shocks that the price of the demolition is exposed to are the cause of the increasing shocks of construction costs. However, there is no relationship between negative shocks. On the other hand, the positive shocks in the TR Demo variable are the cause of positive shocks in the CCI variable, and negative shocks in the TR Demo variable are the cause of negative shocks in the CCI variable. Unlike the USD-based price, lowering shocks in the TR price are the cause of negative shocks in the construction cost. 
Table 5. Asymmetric causality test results

\begin{tabular}{lrrrrrrrrr}
\hline \multicolumn{1}{c}{ Values } & \multicolumn{3}{c}{ USD Demo $\rightarrow$ Construction } & \multicolumn{4}{c}{ TR Demo $\rightarrow$ Construction } \\
& & $\mathbf{D}^{+} \mathbf{C}^{+}$ & $\mathbf{D}^{+} \mathbf{C}^{-}$ & $\mathbf{D}^{-} \mathbf{C}^{-}$ & $\mathbf{D}^{-} \mathbf{C}^{+}$ & $\mathbf{D}^{+} \mathbf{C}^{+}$ & $\mathbf{D}^{+} \mathbf{C}^{-}$ & $\mathbf{D}^{-} \mathbf{C}^{-}$ & $\mathbf{D}^{-} \mathbf{C}^{+}$ \\
\hline Optimal Lag; VAR(p) & & 4 & 1 & 2 & 1 & 4 & 1 & 3 & 1 \\
Additional Lags & & 1 & 1 & 1 & 1 & 1 & 1 & 1 & 1 \\
Test Stat (MWALD) & & 7.97 & 0.04 & 0.69 & 0.28 & 14.0 & 0.46 & 8.12 & 0.24 \\
Asym. chi-sq. p-value & & $0.09^{*}$ & 0.83 & 0.70 & 0.59 & $0.00^{* * *}$ & 0.49 & $0.04^{* *}$ & 0.62 \\
& $1 \%$ & 34.2 & 11.2 & 17.4 & 10.2 & 35.0 & 14.5 & 31.0 & 13.3 \\
Critical Val. & $5 \%$ & 16.5 & 5.04 & 10.5 & 5.50 & 17.0 & 5.39 & 17.1 & 5.47 \\
& $10 \%$ & 11.6 & 3.14 & 6.99 & 1.05 & 11.4 & 3.04 & 11.3 & 3.17 \\
\hline
\end{tabular}

Note: Significance levels: ${ }^{*} 10 \%,{ }^{* *} 5 \%,{ }^{* * *} 1 \%$.

\section{Conclusion}

The impact of Turkish demolition prices, which is one of the major ship demolition countries in the world, on construction costs have been investigated through Construction Cost Index. Although the share of ship scrap in the total steel market is quite small, it is likely that there will be a significant relationship as the steel from the ship demolition is mostly used in the domestic market. In addition, as the demolition price is affected by both the maritime market and the steel market, it is likely to follow a parallel line with general steel prices in the market. In this respect, construction cost changes since the general steel prices are also associated with demolition prices. However, as the subject also has a maritime side, the relationship is not clear and becomes partially complicated. Especially, developments in the freight market affect the number of ships sent to the demolition (Açlk and Başer, 2017) and demolition prices (Açık and Başer, 2018) consequently. Taking into account all of these, the relationship between demolition price and construction cost is likely to be nonlinear.

Although the main focus of the study is the asymmetric causality method, standard linear causality analysis is also applied to show that the relationship between the variables is not linear. Following the reaching of insignificant results from the linear method, the nonlinearity is tested, and asymmetrical causality analysis is applied. In the USD based prices, only one significant relationship is obtained from four possible combinations, and this proves the accuracy of selecting the method used. Only the positive shocks in the demolition price are determined as the cause of the positive shocks in the Construction Cost Index. However, a negative response to a negative impact in the linear method is also a strong possibility. On the other hand, in the TL based prices, causality from negative shocks in demolition prices to negative shocks in construction costs have been spotted, in addition to the causality spotted between positive shocks as in the case of previous currency.

The double causal relations from the TL based prices are probably due to the imported materials that are included in the construction cost basket. Since TL based demolition price is negatively affected by the decrease in the exchange rate as well as the decrease in the USD based demolition price, downward movements in the construction cost occur when the TL based price decreases. Accordingly, positive shocks in the demolition prices cause positive shocks in the construction cost index, which may be the result of both other kind of imported materials and the price of steel.
It is hoped that the findings obtained for the construction sector provide partial useful results for risk minimization and future foresight. Especially the positive shocks in scrap prices may have a positive impact on construction costs, which may directly affect the profitability of firms in the sector. In this context, considering the general parallel movement of the demolition prices with the developments in the freight market, it is suggested that firms in the construction sector should observe the trends in the freight market while pricing for their products, as the profitability of the firms can be affected significantly due to the fluctuations in demolition prices in the period between construction and sales.

In the literature, the interaction of demolition prices with the steel market is partly examined, however, the impact on construction costs is not examined by this approach. In this respect, it is thought that the originality of this study is related both to the unique subject and to the use of asymmetric causality method for the first time.

As a constraint to the study, only the Construction Cost Index data starting from 2015 could be reached. Better results can be obtained with a longer time interval. Similar relations can also be tested for other major demolition countries and more generalizable results can be obtained. In addition, Construction Cost Index can be examined separately according to the possible sub-indices, and the relationship between the steel-based index and demolition price can be considered in a more concrete manner.

\section{Conflict of Interest}

The authors declare that there is no conflict of interest.

\section{References}

Açık, A. \& Başer, S. Ö. (2018a). The relationship between freight rates and demolition prices. Journal of International Trade and Economic Researches, 2(1): 16-32.

Açık, A. \& Başer, S. Ö. (2018b). Market efficiency in ship demolition prices. Proceedings of the International Conference on Empirical Economics and Social Sciences, Bandirma, Turkey, pp. 780-792.

Açık, A. \& Başer, S. Ö. (2017). The relationship between freight revenues and vessel disposal decisions. Journal of Research in Economics, Politics \& Finance, 2(2): 96-112.

Allum, S. (2013). Residual value insurance in the maritime sector. In: Intellectual Property Valuation and Innovation (pp. 135156). Routledge. 
Adıgüzel, U., Bayat, T., Kayhan, S. \& Nazlığlu, Ş. (2013). Oil prices and exchange rates in Brazil, India and Turkey: Time and frequency domain causality analysis. Research Journal of Politics, Economics and Management, 1(1): 49-73.

Athenian Shipbrokers S. A. (2019). Demolition prices. Retrieved in February 10, 2019 from https://hellenicshippingnews.com/.

Bal, D. P. \& Rath, B. N. (2015). Nonlinear causality between crude oil price and exchange rate: A comparative study of China and India. Energy Economics, 51: 149-156.

Brock, W., Dechert, D., Sheinkman, J. \& LeBaron, B. (1996). A test for independence based on the correlation dimension. Econometric Reviews, 15(3): 197-235.

Brock, W., Dechect, W. \& Scheinkman, J. (1987). A test for independence based on the correlation dimension. Working Paper. Department of Economics, University of Wisconsin, Madison.

Chiou-Wei, S. Z., Chen, C. F. \& Zhu, Z. (2008). Economic growth and energy consumption revisited-Evidence from linear and nonlinear Granger causality. Energy Economics, 30(6): 30633076.

Dickey, D. A. \& Fuller, W. A. (1979). Distribution of the estimators for autoregressive time series with a unit root. Journal of the American Statistical Association, 74(366a): 427-431.

Granger, C. W. (1969). Investigating causal relations by econometric models and cross-spectral methods. Econometrica: Journal of the Econometric Society, 37(3): 424-438.

Hatemi-J, A. (2012a). Asymmetric causality tests with an application. Empirical Economics, 43(1): 447-456.

Hatemi-J, A. (2012b). Is the UAE stock market integrated with the USA stock market? New evidence from asymmetric causality testing. Research in International Business and Finance, 26(2): 273-280.

Hatemi-J, A. \& Uddin, G. S. (2012). Is the causal nexus of energy utilization and economic growth asymmetric in the US?. Economic Systems, 36(3): 461-469.

Kagkarakis, N. (2017). The effect of vessel supply on ship-demolition prices. Eurasian Journal of Economics and Finance, 5(1): 7894.

Kagkarakis, N. D., Merikas, A. G. \& Merika, A. (2016). Modelling and forecasting the demolition market in shipping. Maritime Policy \& Management, 43(8): 1021-1035.

Karlis, T. \& Polemis, D. (2016). Ship demolition activity: A monetary flow process approach. Pomorstvo, 30(2): 128-132.
Knapp, S., Kumar, S. N. \& Remijn, A. B. (2008). Econometric analysis of the ship demolition market. Marine Policy, 32(6): 1023 1036.

Kumar, S. (2017). On the nonlinear relation between crude oil and gold. Resources Policy, 51: 219-224.

Lim, S. Y. \& Ho, C. M. (2013). Nonlinearity in ASEAN-5 export-led growth model: Empirical evidence from nonparametric approach. Economic Modelling, 32: 136-145.

Merikas, A., Merika, A. \& Sharma, A. (2015, January). Exploring price formation in the global ship demolition market. In 2015 Annual Meetings.

Mikelis, N. E. (2007). A statistical overview of ship recycling. Paper Presented at the International Symposium on Maritime Safety, Security and Environmental Protection, Athens, Greece.

Mikelis, N. E. (2013). Ship recycling markets and the impact of the Hong Kong Convention. Paper Presented at the International Conference on Ship Recycling, Malmo, Sweden.

Shahbaz, M., Van Hoang, T. H., Mahalik, M. K. \& Roubaud, D. (2017). Energy consumption, financial development and economic growth in India: New evidence from a nonlinear and asymmetric analysis. Energy Economics, 63: 199-212.

Strandenes, S. P. (2010). Economics of the Markets for Ships, p. $217-$ 234. In: Grammenos, C. (Eds.), The handbook of maritime economics and business. 2nd ed. London, UK: Lloyd's List. 1096p.

TCMB (2019). Exchange rates. Retrieved in February 10, 2019 from https://evds2.tcmb.gov.tr/index.php?/evds/serieMarket/\#co llapse_2.

Toda, H. Y. \& Yamamoto, T. (1995). Statistical inference in vector autoregressions with possibly integrated processes. Journal of Econometrics, 66: 225-250.

Tugcu, C. T. \& Topcu, M. (2018). Total, renewable and non-renewable energy consumption and economic growth: Revisiting the issue with an asymmetric point of view. Energy, 152: 64-74.

TUIK (2019). Construction Cost Index. Retrieved in February 10, 2019 from http://tuik.gov.tr/PreTablo.do?alt_id=1077.

Umar, M. \& Dahalan, J. (2016). An application of asymmetric TodaYamamoto causality on exchange rate-inflation differentials in emerging economies. International Journal of Economics and Financial Issues, 6(2): 420-426.

Yin, J. \& Fan, L. (2018). Survival analysis of the world ship demolition market. Transport Policy, 63: 141-156. 